\title{
SOBRE IDENTIDADES Y NACIONALISMOS (CONTRASTES METODOLÓGICOS Y EPISTEMOLÓGICOS)
}

\author{
María Amoretti Hurtado
}

\begin{abstract}
RESUMEN
En este artículo se ponen en diálogo investigaciones filológicas e históricas en torno a la identidad nacional en Costa Rica, con el fin de crear interrogantes metodológicas y epistemológicas dentro de un contexto interdisciplinario que continúe promoviendo la cooperación en esos campos. Para una mejor comprensión del debate que se presenta en este trabajo, se le recomienda al lector la lectura de los avances de investigación aquí implicados y contrastados, señalados por lo demás en la bibliografía final de este artículo.
\end{abstract}

\begin{abstract}
Philological and historical investigations regarding national identity in Costa Rica establish a dialogue in this article, in order to create methodological and epistemological questions inside an interdisciplinary context which continues to promote cooperation between these fields. For a better comprehension of the debate displayed in this article, it is advisable to read the investigation previews implied and contrasted here, and which are also shown in the final bibliography of this article.
\end{abstract}

La importancia del café en el desarrollo cultural e institucional costarricense es ya un lugar común en los discursos históricos, pero habría que seguir insistiendo, sin embargo, en que el café, además de instituir en Costa Rica un modo de producción que va a generar agentes particulares y relaciones específicas de producción, engendra, sobre todo, un microsistema semiótico ideológico.

Este microsistema semiótico ideológico, por medio de elaboraciones cada vez más intelectualizadas y coyunturales, acabará transformándose en el ideologema que va a constituir posteriormente el núcleo del sujeto cultural. Este microsistema semiótico ideológico se impone en un momento dado dentro del discurso social y será utilizado más adelante para la invención de la nacionalidad y la nación. Hemos destacado la palabra utilizado porque es justamente en esa precisión en que estriba nuestro principal desacuerdo con algunos de los estudios que sobre el nacimiento de la identidad nacional se han elaborado, muy concretamente los estudios de Steven Palmer y algunas conclusiones de otros historiadores como es el caso de Víctor Hugo Acuña ${ }^{1}$. Para Palmer la identidad nacional costarricense solamente empieza a formarse en la década de 1880. Para Acuña, ya desde la fundación de la República en 1848 comienza a darse la idea de nación aplicada a una nación costarricense, pero el desarrollo de la definición nacional se mantiene dentro de un marco discursivo estrictamente político hasta 
1949. Para Acuña, la naturalización de la idea nacional costarricense, la pretensión de una continuidad ético-política, es algo mucho más reciente y, según este autor, es un aporte sobre todo de los ideólogos e historiadores del Partido Liberación Nacional.

La discrepancia entre estos dos autores al respecto, puede que no lo sea tanto si intentamos un acercamiento a esta problemática de identidades y nacionalismos desde otro ángulo. Si volvemos a la afirmación inicial de este trabajo, habría que precisar que el surgimiento de un microsistema semiótico ideológico a partir de la producción cafetalera, en realidad no es más que la reelaboración de un texto semiótico previo que se había instaurado en la época colonial a partir de su propia praxis, es decir, del hecho de que la vida colonial costarricense estuviera dominada por la actividad agrícola. Con el advenimiento de la actividad cafetalera y su particular modo organizativo (la fragmentación espacial, su producción que es una especie de experiencia colectiva de orden privado, el pequeño productor independiente, etc.), ese texto semiótico se reforzó y se ajustó a los intereses del naciente estado dando pie a la elaboración de una imagen rousseauniana del pequeño propietario, la casita, la familia unida y una tierra generosa que retribuye el esfuerzo de estos hombres que viven dentro de una sociedad armónica. Así pues, el café se encuentra ligado a la concepción de la nacionalidad, no sólo en Costa Rica sino también en muchos otros países del área. En el nuestro es, además, símbolo nacional y la literatura se ocupa de él precisamente en la época de consolidación del discurso nacional no sólo como simple escenario, sino además como metáfora de la evolución del país ("El grano de oro" y La Propia de Magón, por ejemplo). Del campo morfogenético café como unidad semiótico ideológica, la literatura costarricense abunda en la representación de la pequeña propiedad agrícola y la mitología nacional se aferra a ella bajo diferentes imágenes. La casita, la familia unida, la ausencia de lucha de clases en una sociedad patriarcal y otros "cafemas" más, son las imágenes claves ${ }^{1}$ del criollismo literario. Se podría afirmar que el café es un factor importante, aunque no el único, en la formación de nuestra cultura y en la invención de una identidad nacional. Cuando se implantan otros cultivos, como el del banano, esta actividad produce fuertes tensiones y dramas por el estigma de la presencia extranjera. El contraste que se da es muy grande ya que, mientras la producción cafetalera se liga a valores políticos y morales (democracia y trabajo), a una ética nacional, la producción bananera es un insulto y un escarnio para la nacionalidad. Prueba de ello es el uso que el presidente González Flores le da a la palabra nacionalismo al denunciar con ella los males de la inversión extranjera cuando se refería a la explotación bananera y petrolera en el país (Acuña 1995: 71). Así pues, en la formación de una ética nacional (el trabajo y la paz por ejemplo) creemos que interviene no sólo la voluntad de un grupo dirigente que emplea para sus fines los servicios de agentes simbolizadores, como lo afirman los colegas historiadores, sino que en ese proceso de invención de una nación hay siempre un sustrato cultural fundamental y otro real y objetivo y ambos deben ser tomados en cuenta, ya que sin ellos ningún intento de revolución simbólica es posible. Pero una cosa es hablar del sujeto nacional y otra es hablar del sujeto cultural y aunque el primero no podría existir sin el segundo, ambos tienen una historia diferente. El sujeto nacional puede y debe tener una fecha de invención, mientras que el sujeto cultural no puede ni debe tenerla, pues este último -como lo veremos en la disquisición teórica al final de este artículo-, está hecho de elementos dóxicos que por su constante transferencia terminan borrando sus marcas de origen.

Con el nacimiento del estado moderno nacen los nacionalismos y con ellos emerge el concepto de nación y nacionalidad; en el discurso social de las comunidades así organizadas circula una unidad funcional, significativa y significante por antonomasia, que define los 
límites de la comunidad ideológica; esta unidad discursiva es precisamente el nacionalismo y sus condiciones de posibilidad están ligadas a la propia existencia del estado.

Palmer y Acuña así lo señalan también; para ellos igualmente, la nación es el producto final de un proceso de nacionalización realizado por el Estado en una orientación que va de arriba hacia abajo y en la cual intervienen una serie de agentes intelectuales que éste emplea para sus fines con el propósito de nacionalizar y, por ende, estatificar la idea de un sujeto nacional que justifique su acción.

En esa idea matriz que abre y cierra como tesis central muchos de los artículos dedicados al tópico de nacionalismo o identidad nacional, se señala constantemente un error de enfoque de la historiografía tradicional, la cual hacía de la idea de la nacionalidad y la nación, nociones naturales, reificaciones de fenómenos que, justamente por históricos, tienen fechas de invención y emergen movidos por intereses específicos. Si bien esta tesis -quizá la más fuerte de las que se plantean en esos escritos- de la naturaleza ficcional de la nación y la nacionalidad, nos parece de lo más saludable y concordamos en que el ajuste de foco que proponen los estimables historiadores es necesario para una conciencia crítica de verdades que se nos ofrecen como dogmas intemporales; creemos, sin embargo, que se sigue dando un peso excesivo a una especie de voluntarismo político casi siempre infalible. Como su nombre lo indica, nacionalismo es el discurso que da cuenta de la emergencia de un objeto llamado nación, pero que no es sino parte de una globalidad mayor a la que nosotros llamamos cultura. La identidad nacional es una representación que deriva su eficiencia ideológica solo en tanto sea otra representación de la identidad cultural, la cual es anterior a ella. Es aquí donde radica nuestra divergencia epistemológica con respecto a los estudios de los colegas historiadores ya citados. Luego volveremos a esto.

Si los discursos nacionalistas son de hechura estatal es porque esta es la única instancia capacitada para darle una legitimación oficial a dichos discursos, para estatizarlos. Aunque Palmer muy particularmente acepta la capacidad de réplica de la cultura oral y popular, no le da la importancia debida, para comprobar esto basta con darle una rápida revisión a los tipos de fuentes que él y Acuña utilizan en esos artículos: monumentos, discursos presidenciales, artículos periodísticos. Al señalar Acuña la necesidad de no recurrir a textos de los grandes pensadores o al pensamiento sistematizado, como él lo llama, sino a documentos más ordinarios, pareciera querer evitar la parte más construida o intelectualizada en los conceptos que él rastrea (entre ellos el de "nación"), con el propósito de encontrar en el manejo de esas nociones su contenido cultural. Tampoco recurrirá, aclara él en la introducción de su artículo, al vocabulario político de la gente común, sino que se tratará del vocabulario político de los sectores dominantes. Dadas estas elecciones es extraño encontrar entre las conclusiones de Acuña una declaración que pareciera expresar cierto dejo de decepción cuando afirma que "en el corpus documental analizado no es fácil discernir el contenido cultural del nacionalismo oficial costarricense: por ejemplo, nunca se exaltan en esos textos las figuras de Juan Santamaría y Juan Rafael Mora" (Acuña 1995: 72). Tiene por ello mucha razón el historiador cuando puntualiza que ese trabajo es tan solo un análisis preliminar que debe ser cotejado o confrontado con otro tipo de documentos los cuales, agregaríamos nosotros, podrían ser textos literarios, si de discernir el contenido cultural del nacionalismo costarricense se trata. La dificultad en discernir el contenido cultural del nacionalismo oficial costarricense en el trabajo de Acuña se debe, a nuestro juicio, a dos razones: la naturaleza de las fuentes elegidas y al sustrato epistemológico que subyace en la metodología misma del manejo de esas fuentes. Es posible que un análisis de esos conceptos atendiendo a las eventuales estructuraciones que estos sufran en los textos y 
considerando los campos morfogenéticos en que se involucran, permita extraer, o visualizar al menos, las representaciones culturales que los sustentan. Como ya se ha logrado, por ejemplo, en el análisis sociocrítico de un documento como el discurso de la toma de posesión del Presidente Rafael Ángel Calderón Fournier y al cual nos referiremos más adelante.

Volviendo a la tesis de la manufactura estatal de todo discurso nacionalista, Palmer tiene razón en ubicar la invención de la identidad nacional en la década de los ochenta en el siglo XIX; ya que sólo es a partir de esa fecha que se puede detectar un esfuerzo sistemático por crear un sujeto nacional. El hecho de que a partir de 1848, como lo subraya Acuña, aparezca el concepto de nación aplicado a Costa Rica, no significa ello necesariamente la emergencia de un nacionalismo propiamente dicho, sino tan sólo el señalamiento de una identidad cultural, cuyo acento político se limita únicamente a la idea de su integridad territorial y su soberanía. El nacionalismo, la nacionalidad, comenzará su proceso de constitución sólo en el momento en que la instancia política conozca y reconozca esa identidad cultural y en ese mismo acto y de forma reversible, la entidad política se apropie de los textos culturales convirtiéndolos en su soporte ideológico por excelencia. Aquí es donde encontramos un vacío en la investigación de Palmer, pues si su trabajo reside fundamentalmente en describir los procescs de la creación simbólica en la invención de una nación, los documentos literarios debieron ser tomados en cuenta ya que ellos participaron, como componentes también de esa historia, en la elaboración de esos símbolos y participaron incluso tal vez con mayor eficacia que los monumentos escultóricos, gracias a su poder interpelativo. Por otro lado, si se tomara en cuenta este tipo de fuentes, se vería, además, que el proceso de elaboración de esa mitología no fue sin conflictos y contradicciones, como parece dar a entender Palmer a través de ciertos comentarios suyos sobre la eficacia de las estrategias empleadas por la clase dirigente. Entre los textos literarios que debieron considerarse de alguna manera, figura muy especialmente el Himno Nacional, el cual constituye la oficialización del imaginario de la nacionalidad, documento que por lo demás, se ubica justamente en el instante en que Palmer considera que se da la cristalización del discurso nacionalista. Nos llama la atención el hecho de que Palmer apenas haga mención de este monumento en una nota; referencia en la cual vemos un error interpretativo o carencia de información, ya que el Estado no oficializó en el momento de adopción del texto -como él lo afirma- la letra del Himno compuesta por Billo Zeledón. Como se recuerda en nuestro análisis del Himno Nacional, esa oficialización no se logró sino muchos años después, en 1949, y por decisión de la Junta Fundadora de la Segunda República, lo cual parece coincidir más con las ideas de Acuña en cuanto a que el proceso de invención de la nación costarricense tarda más tiempo en madurar de lo que Palmer cree y afirma. Esta última idea coincide con las premisas teóricas que expondremos al final de este artículo y con algunas de nuestras conclusiones en el análisis de identidad nacional que realizamos en Debajo del Canto. En resumen, el desacuerdo Palmer-Acuña reside en que éste último considera que "el proceso de invención de la nación costarricense se inició más temprano y tardó más tiempo en madurar" de lo que Palmer supone (Acuña 1995: 72).

En un análisis de un relato costumbrista de Magón es factible reconstituir, gracias al análisis semántico y semiótico de sus estructuraciones -cosa que ya hemos logrado- algunas respuestas a preguntas que del desacuerdo Palmer-Acuña han surgido. Entre ellas:

1. ¿Por qué Juan Santamaría no aparece en los discursos presidenciales? Es decir, ¿por qué no es posible discernir en ellos contenidos culturales? 
2. ¿Cuál es el grado efectivo de poder identificatorio de esta imagen?

3. ¿Por qué Santamaría desplaza al campesino como ideologema fundante en el discurso del nacionalismo liberal?

4. ¿Por qué, sin embargo, en la letra del Himno Nacional vuelve el campesino a recuperar su posición de ideologema?

Las respuestas a estas interrogantes se encuentran en una noción clave por cuanto es un paradigma englobante; nos referimos a las ya mencionadas nociones de cultura y sujeto cultural y otras conexas como la de texto cultural e ideologema. Con ellas regresamos nuevamente al punto crucial de nuestros desacuerdos epistemológicos, pero todavía no es el momento de teorizar. Volviendo a lo que de nuestro estudio de "El clis de sol" logramos determinar a propósito de todas estas inquietudes, nos gustaría aclararle al lector que, para no perder el foco de lo que en este momento nos interesa, no entraremos en el detalle del análisis filológico que nos condujo a hilar esas conclusiones y, en su defecto, nos permitimos referirlo al artículo titulado "Dos vivazos y un tonto en un certamen de mentiras" publicado en Káñina. He aquí, entonces, por lo pronto, las conclusiones concernientes a las mencionadas inquietudes:

1. En "El clis de sol", el campesino es la figura central por antonomasia .

2. Si bien para estas fechas, última década del siglo XIX, con la invención de Juan Santamaría ya se habia concretado el sujeto nacional, en el campo literario todavía se discutía la posibilidad de literaturización del campesino y su universo. La polémica nacionalista en el campo literario se centró en la discusión alrededor de esta figura, el concho, entendido como el sujeto popular, el pueblo, y su posibilidad de literaturización o consagración patrimonial.

3. El propósito del autor de "El clis de sol" es la desvalorización de ese sujeto popular, gesto paradójico en quien había defendido durante la mencionada polémica la literaturización de "lo nuestro"; pero gesto consecuente si se acepta la idea de Acuña de que los liberales como Magón, no fueron tan "nacionalistas" como se supone y de que, en la polémica, Magón estaba más seducido por los alcances de un modo genérico (el costumbrismo) que por un nacionalismo así entendido. Por otro lado, esa afirmación de Acuña relativa al pseudonacionalismo de los liberales, nosotros la expresaríamos de otro modo, del modo en que los contenidos implícitos del texto magoniano lo dan a leer: los liberales no tomarían de su propio caldo, ya que la naturalización de su invención es obviamente tan sólo para los demás. De ahí el guiño de ojo que Magón hace constantemente a su lector.

4. El instrumento de transformación cultural que los historiadores ubican a partir de 1850 , la educación, tiene una función contradictoria como reproductor de la identidad nacional pues es, sobre todo, mecanismo de exclusión y distanciamiento de esa misma identidad, tal y como lo da a leer este texto de Magón.

5. Así, el relato evidencia la fragilidad de la invención nacional en el mismo instante en que, con la aparición de textos como este, se pretende reivindicar lo nuestro como valor literario aceptable, de un modo tan sospechosamente contradictorio.

6. El argumento elegido en el relato de marras bordea la problemática del racismo científico (Palmer 1995), el cual es pseudocientíficamente reconfigurado por el campesino del texto al justificar los rasgos europeos -simplemente blancos para él- de sus hijas mellizas, gracias a los efectos de un eclipse solar. 
7. En ese componente étnico de la imago nacional, la parodia de ciertas prácticas discursivas (científicas, biológicas, genéticas) del relato pone en evidencia la ficcionalización de la última etapa del nacionalismo descrito por Palmer (Palmer 1992).

8. Pero también se pone en evidencia que en esa reinversión de valores con respecto al campesino, del cual se da una caracterización harto despreciativa, se niega al mismo tiempo cualquier cualidad heroica posible de su parte ya que, en el texto, éste es la representación invertida de un ideal.

9. En consecuencia, dentro de esta lógica que emerge del fondo del texto, el campesino soldado no es posible, pues se le niega la dignidad del héroe épico; con esto último se pone en duda, consecuentemente, la feliz recepción de la invención de Juan, la cual aparece en los textos de Palmer como una recepción no problematizada, jamás cuestionada por el pueblo, quien se ve reflejado en ella como en un espejo.

10. Existe en la tradición oral, por lo demás, una evidencia de un cierto rechazo a esa imagen épica con que el simbolizador nacionalista quiso rodear la figura de Juan el soldado. Nos referimos a la lexía de "el empujón", de la que curiosamente ninguno de los historiadores se ocupa. La leyenda de Juan es también la leyenda del empujón y esta pone en evidencia el escepticismo en cuanto a la capacidad épica del sujeto cultural. Esta percepción de Juan Santamaría está implícitamente presente en otro de los relatos de Magón, uno titulado "Cal de concha". En este texto, el protagonista -que significativamente también se llama Juan, se ufana de haber sido uno de los combatientes en la guerra del 56, pero al mostrar sus heridas, por la localización y forma de éstas, el narrador de Magón socarronamente deja entrever que sólo pudieron ser conferidas durante una situación de fuga.

11. La identificación del campesino de "El clis de sol" con la imagen que le proyecta su cultivado interlocutor y narrador, si bien le es nefasta por inferiorizante, es sin embargo asumida; lo anterior corrobora que aunque las imágenes sociales del nacionalismo son una invención, son una invención no sólo necesaria sino también inevitable una vez que emergen los estados modernos. Por eso llevan mucha razón los colegas historiadores cuando aclaran que la nación es el producto final de un proceso de nacionalización realizado por el Estado; por lo tanto, añadimos nosotros, la creación de la nacionalidad es simplemente un eslabón más en la gramática discursiva del nacionalismo, cuyos conceptos de nación y de sujeto nacional se hacen ideológica y estructuralmente necesarios no sólo para la legitimación del Estado y la justificación de su existencia, sino también para la constitución del individuo en una nueva forma sujeto; de ahí que este deba someterse a su apropiación -aunque sea cínicamente, como lo muestra este cuento de Magón-, pues de lo contrario sufriría la exclusión.

12. El cinismo de la forma irónica que domina el estilo de este cuento es la mejor descripción de la estrategia identificatoria que regula las relaciones que el yo mantiene con el otro dentro de la específica comunidad que analizamos a través de sus muestras literarias, es decir, Costa Rica.

13. La cultura sólo existe en la medida en que se diferencia de otras pero, entre los índices de diferenciación, debe comprenderse sobre todo la forma en que se regulan las relaciones del yo con los otros en una particular cultura.

14. Las conductas que esa forma de regulación genera y organiza son la materialidad más evidente del modo en que la cultura se reproduce en los sujetos. 
15. Remitir la formación de la nacionalidad a la exclusiva voluntad del grupo dirigente es limitar el proceso únicamente a prácticas sociales institucionalizadas y más específicamente estatales.

16. Hay un factor no consciente que gobierna las representaciones colectivas populares (folklore, mitos, leyendas, dichos, proverbios, etc.) que es una sedimentación transhistórica y heredada, la cual es la manifestación más próxima al sujeto cultural, a esta sedimentación de fuerte contenido dóxico es a la que llamamos texto cultural. Es este contenido dóxico el que recogen, por ejemplo, los textos de Juan Rafael Mora con ocasión de la guerra del 56, por lo que esos textos conforman ya una primera conceptualización antropológica acerca del sujeto cultural costarricense, mas todavía no exactamente del sujeto nacional. En este sentido tiene razón Palmer al denominar "protonacionalismo" a las manifestaciones que se dan en estas primeras etapas del proceso de la constitución de la nacionalidad .

17. Pero si bien no debe confundirse sujeto cultural con sujeto nacional-por razones que explicaremos más adelante-, el discurso nacionalista y su reproducción sólo tiene éxito cuando recurre a los textos culturales; el sujeto nacional es sólo un componente más del sujeto cultural.

18. Los textos culturales, dicho sea de paso, son la manifestación más cercana al sujeto cultural; en el caso de Costa Rica, entre esos textos culturales está el crístico. Ya en nuestro análisis del Himno Nacional demostramos que la existencia de ese texto cultural fue la que hizo plausible la asunción del campesino como imago del sujeto cultural costarricense.

19. Por eso, cuando se "exhuma", como dice Palmer, a Juan Santamaría, la identificación colectiva entró a funcionar no solo por la coyuntura política en que se dio, sino porque a través del texto cultural, Juan fue entronizado como un tipo específico de héroe. Juan Santamaría no es el héroe épico hecho de victorias y derrotas en el fragor de las batallas, sino más bien el héroe crístico pues representa la víctima sacrificial, ya que su gesto (voluntario o no) es un gesto de inmolación. No es casual que su narrativa esté ligada al fuego y al incendio. Tampoco son gratuitos los términos que el propio Palmer emplea en su ensayo, como cuando se refiere a Juan Santamaría como el "Santo laico", la semántica militar que la figura del soldado impone en el héroe exhumado es deconstruida y hasta neutralizada por la imagen de la víctima sacrificial.

20. "Canonizado" este "santo laico" no hay manera de bajarlo del pedestal, a pesar de los "empujones" que se le achaquen, por las mismas restricciones del proceso de beatificación; pero es posible desplazarlo y hasta renegar del él coyunturalmente, según las compensaciones o ajustes que las determinadas situaciones le impongan al sujeto cultural. Así, ya en 1903 es el labriego sencillo quien vuelve a la escena simbólica de primer plano y se mantendrá ahí pues es el núcleo invariable del sujeto cultural costarricense, a pesar de los cambios eventuales de sus anillos semánticos periféricos.

21. Si el momento crucial de la solidificación del discurso nacionalista es 1949, como lo señala Acuña, coincide justamente con la canonización del labriego sencillo en la oficialización del Himno Nacional decretada por la Junta Fundadora de la Segunda República. Este repunte de nacionalismo es necesario para legitimar, justificar y reforzar 
los procesos de nacionalización que se llevarán a cabo a partir de ese momento tanto en la banca como en los servicios públicos, por ejemplo.

22. Lo anterior se completa con la invención de una continuidad ético política, la cual es ilustrada por Acuña con los discursos de Oscar Arias en torno a una democracia costarricense longeva.

23. Pero hay más: en esa misma década de los ochenta en que un nuevo momento de crisis pone a prueba la dureza del núcleo semántico del ideologema identitario, los discursos de Arias evidencian el peso de la figura crística aglutinada esta vez alrededor de la noción de Paz. Acabada su gestión, reconocido su éxito con el otorgamiento del Premio Nobel de la Paz, su discurso debe enfrentarse en la arena simbólica al de su sucesor, Rafael Ángel Calderón Fournier, quien en su discurso de toma de posesión, intenta reconstituir el discurso sobre la paz desde otra óptica ideológica (la de su propio partido) pero acudiendo él también al discurso crístico; así, Calderón Fournier define paz en términos del amor al prójimo, es decir, en términos de justicia social (distribución de la riqueza, protección al desvalido, etc.). La paz no es ya la ausencia de armas (la abolición del ejército efectuada por el partido contrario), que de por sí era ya una acentuación deconstructiva de la famosa frase de Tomás Guardia "más maestros que soldados"; sino que ahora la paz era la garantía estatal de una cierta calidad de vida (las garantías sociales creadas por su padre), en la que cada uno estaría en paz con su vecino porque tendría lo necesario para vivir; es obvio que en este último contraste vuelven a entrar en juego los elementos del texto cultural crístico, a través de condensados dóxicos cristianos relacionados con la caridad; aunque en este caso particular se jugaba también otra apuesta que implicaba la descalificación del régimen de prioridades del gobierno saliente; por eso, más que el concepto de caridad, allí se presupone un contenido dóxico cristiano más particularizante y folklórico, del tipo proverbial "la caridad comienza por casa"; por medio de preasertados como esos, se aseguraba la aceptación de las propuestas del nuevo gobierno, las cuales consistían en invertir la jerarquía o el orden de las determinaciones entre política doméstica y política exterior, prometiendo una mayor atención a los asuntos concernientes a la primera.

24. ¿Cómo explicar que cualquiera de la reconfiguraciones que acabamos de señalar, por más elaboradas intelectualmente que se den, se asientan siempre en el mismo núcleo semántico del texto cultural crístico? La única explicación que se nos manifiesta es la que hemos venido proponiendo : el sujeto nacional es sólo otra representación del sujeto cultural.

Ahora sí consideramos oportuno el momento para teorizar un poco. Ofrecemos por ello, a continuación, el desarrollo de una noción acuñada en el Instituto Internacional de Sociocrítica por Edmond Cros (1995), la cual nos parece de invaluable utilidad en los estudios sobre identidad pues provee un apoyo teórico de base que parece faltar en muchas de esas investigaciones. Junto a la noción de sujeto cultural, se han construido dos conceptos más de igual importancia, ellos son el texto cultural y el ideologema. La razón por la cual el instituto se ha dedicado a teorizar aspectos como estos es que justamente el estudio de las identidades es una de sus investigaciones prioritarias; prueba de ello es que en el últino Congreso Internacional de Sociocrítica, llevado a cabo en Marruecos al final de 1995, se aprobó con: dad de investigación para todos los centros adscritos, la problemática de las identidades micro 
y macroregionales y las formas de colonización del imaginario y sus consecuencias tanto en la creación cultural como en los demás campos de la actividad humana.

El sujeto cultural se define como una instancia de discurso investida por el yo en el que la cultura se reproduce. La cultura se entiende aquí como un bien simbólico colectivo que sólo existe porque es colectivamente compartida, de ahí que el sujeto puede haber asimilado o interiorizado más o menos la cultura a la que pertenece, pero no hay ninguna acción sobre ella a nivel individual. De modo que el sujeto cultural es una instancia que subsume todos los individuos de una misma colectividad y es fundamentalmente de naturaleza ideológica. Su función objetiva es, en efecto, integrar en un mismo conjunto todos los individuos, pero remitiéndolos al mismo tiempo a su respectiva posición de clase, en la medida en que cada una de esas clases sociales se apropia de modos diferentes de ese bien colectivo. Este último funcionamiento es lo que hemos mostrado ampliamente en "El clis de sol"; allí se explicitaron efectivamente las distancias que separan en este plano a un individuo de otro individuo, distancias que corresponden a variaciones en el grado de apropiación de ese bien colectivo que es el sujeto cultural; a este respecto la importancia del análisis de ese cuento estriba en que:

1. Muestra que el mecanismo básico de ese funcionamiento de la cultura es el lenguaje y las diferentes prácticas discursivas. La palabra reúne a los individuos en las mismas creencias para separarlos después. En esa especie de disglosia que ofrece este texto de Magón se reproduce la diferenciación; la palabra es la que mejor separa y remite a cada uno a su posición de clase.

2. Explicita la connivencia en un consabido inenunciable e inconfesable como requisito sine qua non de membresía social. Por ello, este consabido habita más en la enunciación que en el enunciado. Es en el modo irónico de la modalidad enunciativa donde se manifiestan los síntomas de lo que nosotros hemos dado en llamar una identificación conflictiva ya que en esos textos la identidad sólo finge ser asumida, se trata de una identificación irónica que revela que el factor cohesionante no está en el enunciado, sinn más allá de este, en los preasertados que habitan la doxa de los textos culturales yue articulan estos relatos en el nivel implícito.

3. El texto entero se convierte en demostración al ser él mismo el ejercicio o actuación de los dos principios precedentes.

Los dos principios enunciados bastan para comprender por qué el sujeto cultural es la instancia que regula las relaciones que el yo mantiene con los otros.

El texto cultural es la manifestación más próxima al sujeto cultural. Este texto es el mismo para todos, funciona como un texto latente, es de naturaleza doxológica y está constituido por un núcleo de concreciones semánticas, las cuales mantienen entre ellas relaciones que no pueden ser alteradas; por lo tanto, ese núcleo semántico es un núcleo duro. El texto cultural es retransmitido infinitamente hasta el punto de considerarse un bien colectivo cuyas marcas de identificación original han desaparecido. Por eso no tiene fecha de invención. Esta última idea complementa la tesis de Acuña en el sentido de que la solidificación del nacionalismo costarricense sólo ocurre después de 1949, cuando se fusionan en el tiempo primordial del origen absoluto tanto el texto de la cultura como el discurso de la identidad nacional y así ambos se funden en una sola unidad acrónica. 
En la retransmisión constante del esquema del texto cultural, este sufre tantas manipulaciones que los elementos secundarios de la periferia se rectifican sin cesar y entrañan series completas de variantes; de modo que es este anillo de variantes el que funciona como protección del núcleo. Así, por ejemplo, en el caso de Juan Santamaría, esta creación no sería más que una variante del núcleo de nuestro texto cultural por antonomasia, el texto crístico; otras variantes estarían representadas por las dominantes semánticas de la paz, la justicia, la humildad, la ingenuidad y hasta la ignorancia, dependiendo de la formación ideológico-discursiva en que se inserte; el núcleo de ese texto cultural está constituido por la doxología crística, como ya lo hemos afirmado. Su naturaleza latente lo acerca más a una simbólica de lo no consciente y no a la voluntad de una inteligencia dirigente, como se desprende de los trabajos de Palmer y Acuña ya referidos; ya que esa misma inteligencia dirigente está también determinada por el mismo texto cultural. Si bien coincidimos en que el discurso nacionalista proviene de las élites en el poder, la eficacia simbólica de ese discurso depende del grado en que la visión propuesta esté fundada en la realidad; esto es, en las afinidades objetivas de las personas que se trata de juntar, es decir, en los textos culturales del sujeto colectivo. Para Bourdieu, el poder simbólico es un poder de consagración o de revelación de las cosas que ya existen, pero que solo comienzan a existir como tal (una nación, por ejemplo) para aquellos que forman parte de ellas, solo cuando es conocida y reconocida (Bourdieu 1988). Esto último es el proceso que Palmer describe cuando habla de la invención de la nación; en otras palabras, lo que Palmer describe es el proceso de simbolización, el cual solo es posible sobre la base de los textos culturales de una sociedad que ya existía como colectividad, aunque tal vez no como nación. Existe nación propiamente dicha solo si hay personas que puedan decir que ellas son la nación. Pero en la cooptación, en el acto mismo del reclutamiento, lo esencial son dos efectos: el de metonimia y el de metáfora. El de metonimia se da en el paso del yo al nosotros, el cual es precisamente el rasgo más característico del discurso magoniano en su ya célebre pregunta retórica de "cuál de mis lectores, no sabe, no conoció, etc.", en donde de la suma de "mis lectores" y "yo", se crea el sujeto colectivo del "nosotros", que es precisamente colectivo porque compartiendo un consabido que jamás se explicita para mejor compartirlo, "yo" y "mis lectores" funcionan como espejo uno del otro. Por otra parte, el efecto de metáfora no se logra descubriendo similitudes entre los individuos, sino más bien creándolas para convencerlos de una semejanza cohesionadora que hace comunidad y que al mismo tiempo la diferencia de otras comunidades. Así, la literatura es el sistema de la palabra grupal, colectiva, y los textos de Magón son la mejor ilustración de ello en plena etapa nacionalista. El efecto metáfora alcanza su mayor potencial en el momento en que Magón se convierte en historiador de lo que, por estrictamente típico, cuenta; historiador, por tanto, del sentido verdadero de la tipología nacional. A este respecto, recuérdese la frase inicial del texto "El principio de autoridad”, ("¿Quién no sabe en Costa Rica el verdadero significado...?”), el cual comentamos ampliamente en un artículo que publicamos con el título de "Autor o autoridad... cuestión de principios".

Empleando nuevamente otra idea de Bourdieu (1988), el texto cultural podría entenderse como un código maestro que -y esto es de extrema importancia- además de vehiculizar conceptos y valoraciones, representa estructuralmente mecanismos de producción de sentido paradigmáticos. Esto implicaría afirmar al mismo tiempo que el texto cultural provee la forma en que se piensan y se dicen las cosas dentro de una comunidad dada. Ahora que, si se entiende el texto cultural como un código maestro, debe entenderse también como una matriz 
tropeica, dado que gracias al anillo periférico de variantes que proteje su núcleo, el texto cultural puede elaborarse en otras direcciones, como ya lo ilustramos. Es precisamente esta cualidad la que permite la fluctuación de los contornos de una cultura, cuando por razón de las nuevas coyunturas históricas esta debe rectificar sus bordes. En esto, el texto cultural se aproxima al ideologema. Aunque no compartimos en todo la noción de ideologema sugerida por Cros, consideramos que ha sido él quien lo ha precisado mejor y lo ha convertido en un concepto mucho más operatorio.

Podemos definir el ideologema como una unidad funcional y significativa subyacente en un microsistema semiótico ideológico, que se impone en un momento determinado en el discurso social. Se entiende por discurso social una especie de permanencia que forma cierta memoria de la doxa (Angenot 1991). A través del ideologema, al igual que en los textos culturales, se dan ciertas máximas que delimitan el orden dóxico de una cultura. Pero el ideologema se caracteriza, además, por su extraordinaria fluctuación, rasgo que le permite filtrarse e imponerse dentro de diferentes prácticas semióticas. En el caso que nos ocupa, el texto cultural está presentando también esta gran capacidad de ósmosis discursiva, característica del ideologema. Esto último ya lo ilustramos en el caso de las luchas por la hegemonía del discurso sobre la paz en la Costa Rica de los ochenta, en la que se evidenció la fuerza conmutadora del texto cultural crístico al pasar de un discurso al discurso de su adversario, gracias a la labilidad de la periferia de su campo nocional y a la dureza de su núcleo semántico. Esta inestabilidad semántica de la periferia del texto cultural también ha sido detectada por los historiadores mencionados, tanto en el protonacionalismo de Palmer como en las fluctuaciones y ajustes semánticos y semióticos señalados por este mismo autor en el proceso de creación del héroe nacional. Lo mismo se evidencia en la inestabilidad de los conceptos de estado, república, nación y democracia, conceptos claves, según la opinión de Acuña, en el vocabulario político de los estados-naciones modernos. Por eso, según este autor, en la trayectoria de la evolución de esos conceptos es posible rastrear al mismo tiempo el proceso de formación de la identidad nacional en Costa Rica y sus fluctuaciones, de ahí que sus conclusiones atañen sobre todo a esta problemática y, tanto una como los otros, adolecen de esta inestabilidad que les confiere la capacidad osmótica del anillo periférico del texto cultural. Pero es esa misma labilidad periférica del texto cultural, la que lo convierte al mismo tiempo en una fuerza mórfica homogenizadora que, atravesando los discursos sociales, es capaz de reorientarlos políticamente.

Para finalizar hemos de puntualizar que a pesar de las diferencias que hemos señalado en el enfoque epistemológico de los estudios de identidad, hay una coincidencia fundamental con los historiadores citados, cual es la finalidad ética de la investigación cultural: comprender la cultura, no idealizarla. En este sentido nuestra labor en el análisis de los textos literarios y culturales ha sido siempre orientada por esa ética. Y en cuanto al desacuerdo expuesto, creemos que más que desacuerdo, debería interpretarse como una invitación más que estos campos se están haciendo llegar desde hace varios años ya y por intermedio, sobre todo, de la labor interdisciplinaria que se despliega en el Instituto de Identidad Cultural de la Facultad de Letras de la Universidad de Costa Rica y en el Centro de Investigaciones Históricas de la Facultad de Ciencias Sociales de esta misma Universidad. Esta es una invitación a considerar seriamente el texto literario como fuente. Ya Iván Molina nos ha brindado un despliegue asombroso de fuentes de diferente naturaleza que, al menos en nuestro medio, constituyen una revolución teórica y metodológica en el campo de la Historia y cuyos datos constituyen marcos de referencia importantísimos en el campo literario; cito de paso los inventarios de libros, 
los avisos publicitarios en los periódicos y otras. Todas esas fuentes nos traen una historia que parte de lo cotidiano para intentar alcanzar, por medio de las prácticas sociales que organizan nuestros actos y orientan nuestras decisiones, los componentes esenciales de los dispositivos semióticos de nuestra cultura. De esta for ıla la historiografía pierde solemnidad para ganar en profundidad humana y proximidad de lo vivencial. Baste tan sólo considerar la nueva titulología que rubrica muchos de los trabajos de estos nuevos historiadores.

Pero a pesar de todo esto, sigue habiendo un gran ausente: el texto literario .

En un memorable artículo titulado "El texto literario: memoria viva y morfogénesis" (Cros 1995), Edmond Cros señala el advenimiento de la "era de la sospecha" en cuanto a la valorización sin reserva del documento, como uno de los momentos claves en esta evolución de la disciplina histórica. Pero enseguida afirma que, a pesar de ello, el texto literario sigue siendo para los historiadores un tipo de documento del que no se fían porque lo consideran demasiado subjetivo, poco creíble y, en fin, como perteneciente al universo de lo ficticio. Esa es la razón por la cual la mayoría de los historiadores no se interesan, más que marginalmente, en los hechos literarios y, cuando lo hacen, es solo "por una especie de coquetería". Tal parece entonces que el texto literario no es uno de los componentes de la historia. Esta desconsideración del texto literario como fuente es una verdadera lástima, ya que este almacena información de otro nivel de importancia que la que almacena otro tipo de documento. Las concreciones sociohistóricas del texto literario, aunque vehiculizadas bajo formas más o menos complejas, se encuentran estructuradas de modo que ofrecen una jerarquización indicial y evaluativa de la información que pone de relieve los debates fundamentales de su sociedad y los intereses sociales implicados, pues la manera en que esa información funciona en el corazón de la producción de sentido multiplica su capacidad informativa. Como lo afirma Cros, "una aproximación crítica que considere el rol genético que ahí juega el almacenamiento de la información, podría ser una forma de acceso a datos preciosos para la reconstitución histórica" (Cros 1995: 129). Pero también advierte Cros que hay que buscar esa información allí donde ella se encuentra, en el dispositivo semiótico, y no en elementos aislados, tomados en sí, fuera de toda relación con los otros elementos del texto y desestructurando de esta forma su verdadera capacidad informativa. Sólo el sistema semiótico puede dar cuenta del sedimento de socialidad memorizado por el texto.

De qué otra forma se explicaría que un análisis como el que efectuamos del Himno Nacional en el libro Debajo del canto (Amoretti 1987), el cual fue efectuado y sacado a la luz con anterioridad a las publicaciones de Palmer, coincida con éste en lo fundamental. A saber:

1. La nación y la nacionalidad son invenciones, pues el costarricense que se canta en el Himno no es más que un valor, un proyecto de hombre.

2. La ubicación del intertexto matriz justamente en el período de la guerra de 1856, en el período en el que posteriormente Palmer ubicaría lo que él llama "protonacionalismo".

3. Por lo tanto, si bien las señas de identidad consignadas en el Himno son las mismas que establece Mora en sus discursos, serán posteriormente deconstruidas y redistribuidas de otra manera por la conciencia de un Billo Zeledón y su circunstancia sociopolítica.

4. De modo que el análisis no se limita únicamente a la identificación de un documento preciso desde donde el Himno reproduce sus valores (la proclama de Juan Rafael 
Mora), sino que también explica la forma en que las coyunturas sociales y políticas deconstruyen allí esos valores y los reconfiguran.

Todos estos elementos no hacen otra cosa que confirmar por anticipado lo esencial de los resultados del trabajo de Palmer, a saber: que la consolidación del nacionalismo costarricense se da en la última década del siglo XIX, acontecimiento que él ilustra con la inauguración de los monumentos nacionales, entre los que destaca el del soldado Juan. Pero se olvida, como ya lo hemos dicho, del último monumento, el del Himno Nacional. ¿Obedecerá esto al hecho de que Palmer, siguiendo las pautas de una cierta historiografía francesa, considere únicamente obras escultóricas y no necesariamente monumentos verbales? ¿O será parte de ese menosprecio existente todavía a considerar los textos literarios como fuente? Y comparados con la estatua de Juan o con el llamado Monumento Nacional, el Himno Nacional es no sólo el último monumento del proceso que describe Palmer, sino que es además el monumento más eficaz por sus efectos pragmáticos. El Himno Nacional es un rito que marca el cuerpo por los gestos a que obliza: postura del cuerpo, de pie, firmes, recogidos y dignos. El Himno Nacional es una especie de jura por la que el individuo asume los signos disponibles en él, y se apropia de ellos apropiándose ellos de él. En ese gesto del poseso, los signos se expresan en su cuerpo, identificándose él con ellos al mismo tiempo que esos signos lo identifican a él y lo reclutan. Ellos son el agente; él, el objeto apropiado y expropiado. El Himno Nacional es un dispositivo semiótico y pragmático fundamental del "habitus nacional", hecho de relatos, pero sobre todo de ritos, de ritos que se reiteran tan sólo para una reconfirmación de la identidad. Esta es la función y la naturaleza de un texto como el Himno Nacional, al que sin embargo, Palmer no toma en cuenta.

Nuestro análisis del Himno Nacional arroja algunos puntos de coincidencia con Acuña en el sentido de que el proceso de invención de la nación costarricense tardó más tiempo en madurar de lo que supone Palmer (Acuña 1995: 72). Aunque desde los cincuenta en el siglo pasado se dieron brotes de un protonacionalismo que se puede evidenciar en la creación de la música del Himno en 1852, por ejemplo, Palmer tiene mucha razón en fijar el período de consolidación del nacionalismo a partir de 1885 y el período de cristalización en la última década del siglo XIX; el hecho de que la misma música del Himno permanezca muda hasta 1903 apoya esta teoría de Palmer, es decir, confirma que el proceso de simbolización de la nación no se concreta sino en la última década del siglo XIX. Por otro lado, tal y como lo defiende Acuña, esto no quiere decir tampoco que tal simbolización ahí finalice ya que falta todavía su fusión total con el sustrato cultural, lo cual ocurre en el momento en que se hacen coincidir el discurso nacionalista y el texto cultural en el tiempo absoluto, borrándose en ese mismo acto toda fecha de invención o marca de origen de la identidad nacional.

Además, nación, nacionalidad y nacionalismo en general, como ya lo hemos establecido, son elementos claves constitutivos de formaciones discursivas, las cuales, al igual que la cultura y su sujeto, son fuerzas dinámicas sometidas siempre al reequilibrio, como lo afirmamos en las conclusiones de nuestro libro sobre el Himno Nacional, pues : "El orden social no es un equilibrio adquirido que se mantendrá fácilmente, sino un orden amenazado cuyo perpetuo equilibramiento constituye una tarea sin final" (Amoretti 1987: 76). Hoy más que nunca, ese concepto de nación y de identidad nacional se encuentra fuertemente amenazado por el proceso de globalización al que está siendo sometida la sociedad contemporánea y el concepto de Estado se encuentra en franca crisis. ¿Implicará esto un nuevo reacomodo de estos conceptos o su desaparición en favor de una nueva ciudadanía? Si bien es muy pronto 
para responder a esta interrogante con la que se inaugura una nueva centuria y un nuevo milenio, los recientes enfoques en la historia de las identidades representan de alguna manera un golpe de gracia para los nacionalismos, al denunciarlos como mecanismos estratégicos mediante los cuales se camuflan mezquinos intereses particulares bajo la apariencia de una ética universal o colectiva.

\section{Notas}

1. El trabajo de Víctor Hugo Acuña al que me refiero se titula "Historia del vocabulario político en Costa Rica. Estado, república, nación y democracia (1821-1949)" y se encuentra en una publicación que lleva como título Identidades nacionales y Estado Moderno en Centroamérica. Compiladores Arturo Taracena A.Jean Piel. San José: Editorial Universidad de Costa Rica. 1995. El de Steve Palmer se titula "Inventando la nación en Costa Rica (1848-1890)" y forma parte del libro titulado Héroes al gusto y libros de moda. San José: Editorial Porvenir y Plumsock Messoamerican Studies. 1992. De Palmer también se hace breve referencia al artículo titulado "Hacia la "auto-inmigración". El nacionalismo oficial en Costa Rica. 1870-1930", ensayo que es parte del volumen Identidades nacionales y Estado Moderno en Centroamérica, ya citado.

\section{Bibliografía}

Acuña, Víctor Hugo. 1995. "Historia del vocabulario político en Costa Rica. Estado, república, nación y democracia (1821-1949)". En: Taracena A. y Jean Piel (comp.).

Amoretti Hurtado, María. 1997. "Autor y autoridad... cuestión de principios". Káñina. XXII (1), 9-21.

1987. Debajo del canto. San José. Editorial de la Universidad de Costa Rica.

1998. "Dos vivazos y un tonto en un certamen de mentiras". Káñina. XXII (2), 9-27.

Angenot, Marc y Régine Robin. 1991. "La inscripción del discurso social en el texto literario". Sociocrítica. Prácticas textuales. Cultura de fronteras. Amsterdam: Rodopi.

Bourdieu, Pierre. 1988. Cosas Dichas. Buenos Aires: Gedisa.

Cros, Edmond. 1995. D'un sujet a l'autre: Sociocritique et Psychoanalyse. Montpellier.

Palmer, Steve. 1995. "Hacia la "auto-inmigración". El nacionalismo oficial en Costa Rica. 1870-1930". En: Taracena A. y Jean Piel (comp.).

1992. "Inventando la nación en Costa Rica (1848-1890)". Héroes al gusto y libros de moda. San José: Editorial Porvenir y Plumsock Messoamerican Studies.

Taracena, Arturo y Jean Piel (comp.). 1995. Identidades nacionales y Estado Moderno en Centroamérica. San José: Editorial Universidad de Costa Rica. 